\title{
Priming and substrate quality interactions in soil organic matter models
}

\author{
T. Wutzler and M. Reichstein \\ Max Planck Institute for Biogeochemistry, Hans-Knöll-Straße 10, 07745 Jena, Germany \\ Correspondence to: T. Wutzler (twutz@bgc-jena.mpg.de)
}

Received: 18 October 2012 - Published in Biogeosciences Discuss.: 6 December 2012

Revised: 28 February 2013 - Accepted: 5 March 2013 - Published: 26 March 2013

\begin{abstract}
Interactions between different qualities of soil organic matter $(\mathrm{SOM})$ affecting their turnover are rarely represented in models. In this study, we propose three mathematical strategies at different levels of abstraction to represent those interactions. By implementing these strategies into the Introductory Carbon Balance Model (ICBM) and applying them to several scenarios of litter input, we show that the different levels of abstraction are applicable at different timescales. We present a simple one-parameter equation of substrate limitation that can straightforwardly be implemented into other models of SOM dynamics at decadal timescale. The study demonstrates how substrate quality interactions can explain patterns of priming effects, accelerate turnover in FACE experiments, and the slowdown of decomposition in long-term bare fallow experiments as an effect of energy limitation of microbial biomass. The mechanisms of those interactions need to be further scrutinized empirically for a more complete understanding. Overall, substrate quality interactions contribute to both understanding and quantitatively modelling SOM dynamics.
\end{abstract}

\section{Introduction}

The priming effect, i.e. the enhanced or retarded soil organic matter (SOM) decomposition due to amendment of fresh SOM or mineral nitrogen (Jenkinson et al., 1985; Kuzyakov et al., 2000), and the role of microbial biomass controlling decomposition rates have received increasing attention during the last years (Todd-Brown et al. 2012; Treseder et al. 2011; Allison et al. 2010; Guenet et al. 2010; Blagodatskaya and Kuzyakov 2008; Fontaine et al. 2003, but see also older works of Löhnis 1926; Parnas 1975; Smith 1979; Panikov
1995; Ågren and Bosatta 1996). Reasons are that, first, understanding its causes opens perspectives on SOM decomposition and SOM stabilization and, second, because of its potential relevance for understanding feedback to climate warming. Enhanced primary production associated with environmental change may increase decomposition of the large amount of old carbon stored in soils (Jobbagy and Jackson, 2000 ), as this fraction is especially vulnerable to priming (Fontaine et al., 2007). Hence, the increase in SOM inputs by plant litter with enhanced primary productivity may lead to net loss of SOM due to positive priming effects. The priming effect highlights the issue that the decomposition rate of SOM of one quality depends on the amount of SOM of other qualities. This means that there are substrate quality interactions.

In contrast to this substrate quality interaction paradigm, all the widely applied SOM dynamic models (e.g. RothC, Century, Yasso, CASA, Q-model) (Jenkinson and Coleman, 2008; Parton et al., 1988; Liski et al., 2005; Potter et al., 1993; Ågren and Bosatta, 1996) assume that SOM of different qualities decomposes independently of each other; i.e. they neglect substrate quality interactions. For a recent overview see Manzoni and Porporato (2009). In recent decades, several models have been proposed that explicitly account for co-metabolization of different SOM qualities by the microbial biomass of active decomposer to explain substrate interactions and priming effects (Fontaine and Barot, 2005; Fang et al., 2005; Wutzler and Reichstein, 2008; Blagodatsky et al., 2010; Neill and Gignoux, 2006; Moorhead and Sinsabaugh, 2006; Poll et al., 2010). It is now timely to implement those processes into ecosystem models and test whether the SOM quality interactions matter at larger spatial and temporal scales. Implementing the 

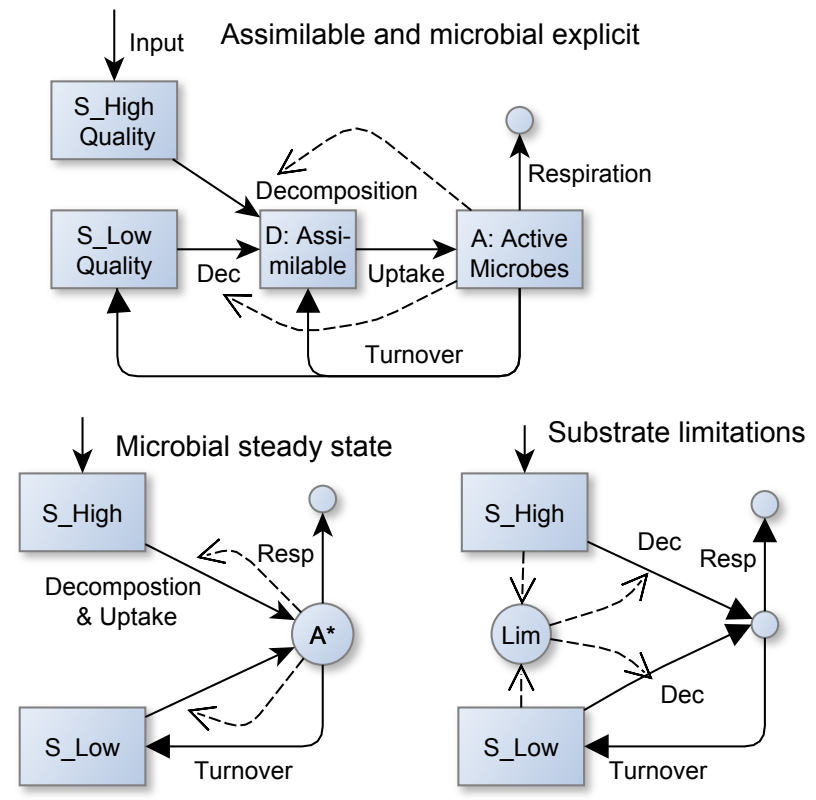

Fig. 1. Basic strategies of implementing substrate interactions. Solid arrows represent carbon fluxes. Dashed arrows highlight further controls. Boxes represent state variables, and circles represent values that are derived from state variables.

details of active microbial biomass in components of global land-surface models running on large spatial extents, however, will increase uncertainty because of additional uncertain model parameters (Hilborn and Mangel, 1997). Hence, an abstraction of those processes is required that still captures the main effects of the interactions of different SOM qualities.

The aims of this paper are as follows: first, to propose basic strategies of representing SOM quality interactions in models (Sect. 1.1); second, to exemplify their implementation (Sect. 2.1); and, third, to compare their advantages and disadvantages for different modelling purposes and settings (remainder of the paper).

\subsection{Basic strategies}

The most detailed strategy we propose explicitly models assimilable organic matter $(\mathrm{OM})$ and active microbial biomass (Fig. 1). By contrast, the most abstract strategy lets the decomposition rate of the lower quality SOM, i.e. with slower decomposition, depend on the amount of high-quality SOM. An intermediate strategy assumes that microbial biomass dynamics are fast compared to other processes and assumes microbial activity to be in steady state with the mineralization flux.

\subsubsection{Explicit assimilable $O M$ and active microbial biomass representation}

Co-metabolization of different substrate qualities is hypothesized to be the main mechanism of substrate interactions (Wutzler and Reichstein, 2008). Decomposition of substrate is not only dependent on the amount of substrate but also on the activity of decomposers. Independent decomposition of SOM qualities is coherent with the assumption that each quality of SOM is decomposed by a specific microbial community and that this community is in steady state with the current pool. In contrast, assuming that the microbial community is able to decompose SOM of different qualities, or that there are interactions between the communities degrading SOM of different qualities, links the decomposition of SOM of one quality to the decomposition of SOM of other qualities. When the microbial community is stimulated by increased availability of high-quality SOM, the decomposition of low-quality SOM can be enhanced too. Hence, the first strategy to implement substrate interactions is to explicitly model microbial activity (Sect. 4.6), or active microbial biomass as a dynamic state variable. The most detailed strategy (Fig. 1 top) assumes that different SOM qualities are decomposed into smaller assimilable compounds, and assumes that microbial growth can be modelled with a single substrate (Monod, 1949). Turnover of microbial biomass can be modelled as the difference between uptake of carbon and respiratory carbon requirements for energy and additional turnover by predation or disturbances that usually increase with microbial biomass.

substrate: $\frac{\mathrm{d} S_{j}}{\mathrm{~d} t}=i_{j}+p_{j} \tau-d_{j}$

assimilable OM: $\quad \frac{\mathrm{d} D}{\mathrm{~d} t}=\sum_{j} d_{j}+p_{\mathrm{D}} \tau-u$

active microbial biomass: $\frac{\mathrm{d} A}{\mathrm{~d} t}=u-r_{\mathrm{g}}-\tau$

decomposition: $d_{j}=l_{e, j}(t) f_{d}\left(S_{j}, A\right)$

uptake: $u=f_{u}(D, A)$

growth respiration: $r_{\mathrm{g}}=(1-\epsilon) u$

microbial turnover: $\quad \tau=f_{\tau}(A)$

Where $j$ denotes the quality of a given substrate, $i_{j}$ is the external input to the system, $p_{j}$ the proportion of microbial turnover feeding to pool $j$, and $\epsilon$ the microbial efficiency or yield. $l_{e, j}(t)$ is a model driver that modifies decomposition fluxes based on time-dependent environmental conditions such as temperature or moisture.

Potentially, there are additional important processes that might be required to be included in this scheme. These include preferential substrate usage, dormancy or sustaining states, and heterogeneity of kinetic parameters between different microbial communities. Those processes can 

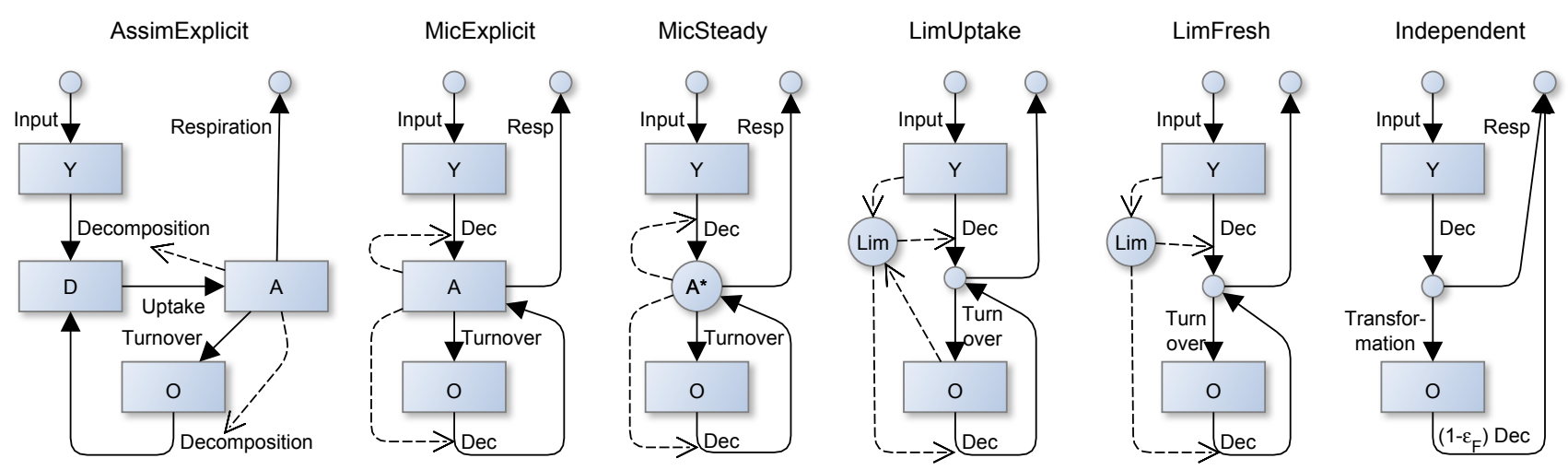

Fig. 2. Structure of the ICBM model variants. Solid arrows denote carbon flows; dashed arrows represent further controls.

actually drive short-term dynamics when monitoring microbial growth over a few days as is commonly done in priming experiments. However, our goal here is to capture the basic dynamics, and we seek to obtain an abstract understanding instead of including more detail.

\subsubsection{Quasi-steady-state active microbial biomass}

Another strategy is to successively increase abstraction from details of the microbial explicit model. The assimilable pool quickly approaches a state where its input equals microbial uptake. Hence, we may set uptake $u=\sum_{j} d_{j}+p_{\mathrm{D}} \tau$. Further, also active microbial biomass approaches a state where growth (depending on mineralization fluxes) equals its turnover. Hence, we can calculate a quasi-steady state (Segel and Slemrod, 1989) of the active microbial biomass for given amounts of available substrates $A^{*}=f\left(S_{j}\right)$. Next, we replace microbial biomass by this steady state in the equations of respiration, microbial turnover, and decomposition (Fig. 1 bottom left). The resulting microbial steady-state model can be reformulated, so that the limitation of decomposition by decomposer activity can be directly expressed by model parameters.

\subsubsection{Substrate limitations}

A coarse strategy is to directly formulate substrate interactions in the decomposition equations as

substrate: $\frac{\mathrm{d} S_{j}}{\mathrm{~d} t}=i_{j}(t)-d_{j}+\sum_{i \neq j} a_{i j} d_{i}$,

decomposition: $\quad d_{j}=l_{e, j}(t) f_{j}\left(S_{1}, \ldots, S_{n}\right)$,

where $a_{i j}$ is the portion of carbon decomposed of pool $i$ that is transferred to pool $j$.

One specialization of this general decomposition formula $d_{j}$ is to specify one common limitation factor, $l_{A}$, for all substrate qualities $j$. This factor depends on the amount of all substrate in all qualities or alternatively depends only on the amount of the high-quality substrate (Fig. 1 bottom right).

decomposition: $d_{j}=l_{A} l_{e, j}(t) f_{d, j}\left(S_{j}\right)$

substrate limitation: $l_{A}=f_{A}\left(S_{1}, \ldots, S_{n}\right)$

The substrate interaction strategy can be applied without any consideration of decomposers. Alternatively, it can also be derived as a further level of abstraction of the quasisteady-state active microbial biomass strategy.

\section{Methods}

\subsection{Implementations to the ICBM}

The basic strategies (Sect. 1.1) are exemplified by implementing them into a series of models that are versions of the Introductory Carbon Balance Model (ICBM) (Andrén and Kätterer, 1997).

The ICBM is a simple two-pool model that shares the basic structure and captures most of the dynamics of more complex pool models for SOM turnover such as RothC and Century. In this study, several variants of the model were developed (Fig. 2), which varied in structural complexity. A more detailed explanation of the model variants and the differential equations are given in Appendix A. Pool names and parameters are described in Table 1. The following text summarizes the main characteristics of the model variants.

\subsubsection{AssimExplicit}

We started implementing substrate interactions with the microbial-explicit strategy. Litter input enters the highquality pool, denoted by $Y$. Decomposition flux of this pool and the decomposition flux of the low-quality pool, denoted by $O$, enters a pool of assimilable carbon, denoted by $D$. Here, the decomposition was first order with respect to substrate $(Y$ or $O)$ but decreased at low microbial activity, which was expressed by the amount of active microbial biomass $A$ : $f_{d}\left(S_{j}, A\right)=k_{j} S_{j} \frac{A}{m_{a}+A}$. With the assumption that active microbial biomass is proportional to a pool 
Table 1. Parameters of the ICBM model variants. + indicates usage in respective model variant.

\begin{tabular}{|c|c|c|c|c|c|c|c|c|}
\hline & Unit & Description & 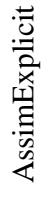 & 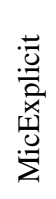 & 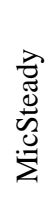 & $\begin{array}{l}\frac{\mathscr{a}}{\tilde{J}} \\
\stackrel{\tilde{a}}{\Xi} \\
\stackrel{\Xi}{\Xi}\end{array}$ & 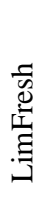 & 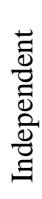 \\
\hline State Variables & & & 4 & 3 & 2 & 2 & 2 & 2 \\
\hline$Y$ & $\mathrm{gCm}^{-2}$ & high-quality substrate (young) & + & + & + & + & + & + \\
\hline$O$ & $\mathrm{gCm}^{-2}$ & low-quality substrate (old ) & + & + & + & + & + & + \\
\hline$A$ & $\mathrm{gCm}^{-2}$ & active microbial biomass & + & + & & & & \\
\hline$D$ & $\mathrm{gCm}^{-2}$ & assimilable organic carbon (dissolved) & + & & & & & \\
\hline Parameters & & & 8 & 6 & 6 & 4 & 4 & 3 \\
\hline$\mu_{\max }$ & $\mathrm{yr}^{-1}$ & maximum growth rate & + & & & & & \\
\hline$m_{\mathrm{D}}$ & $\mathrm{gCm}^{-2}$ & affinity, i.e. half saturation, of uptake & + & & & & & \\
\hline$k_{\mathrm{Y}}$ & $\mathrm{yr}^{-1}$ & decomposition rate of high-quality pool & + & + & + & + & + & + \\
\hline$k_{\mathrm{O}}$ & $\mathrm{yr}^{-1}$ & decomposition rate of low-quality pool & + & + & + & + & + & + \\
\hline$\epsilon$ & $0 \ldots 1$ & microbial efficiency & + & + & + & + & + & + \\
\hline$t_{\mathrm{A}}$ & $\mathrm{yr}^{-1}$ & turnover rate of active microbial biomass & + & + & + & & & \\
\hline$s_{\mathrm{A}}$ & $\mathrm{yr}^{-1}$ & maintenance rate & + & + & + & & & \\
\hline$m_{\mathrm{A}}$ & $\mathrm{gCm}^{-2}$ & half saturation of decomposition & + & + & + & & & \\
\hline$a_{\mathrm{A}}$ & $\mathrm{gCm}^{-2} \mathrm{yr}^{-1}$ & minimum uptake & & & & + & + & \\
\hline \multicolumn{9}{|l|}{ Drivers } \\
\hline$i(t)$ & $\mathrm{gCm}^{-2} \mathrm{yr}^{-1}$ & litter input flux & & & & & & \\
\hline$l_{\mathrm{e}, \mathrm{Y}}(t)$ & $0 . .1$ & environmental effects on $k_{Y}$ & & & & & & \\
\hline$l_{\mathrm{e}, \mathrm{O}}(t)$ & $0 . .1$ & environmental effects on $k_{O}$ & & & & & & \\
\hline
\end{tabular}

of substrate degrading enzymes, this decomposition equation corresponds to the model of Schimel and Weintraub (2003). Microbial uptake from the assimilable pool was modelled according to Monod kinetics. In addition to growth respiration, we included also maintenance respiration, which linearly increased with active microbial biomass. As a first approximation, the entire turnover of the microbial biomass was assigned to the low-quality pool.

The term $l_{\mathrm{e}, \mathrm{j}}(t)=f(T, \mathrm{M}, \ldots)$ incorporates how decomposition rates depend on environmental factors such as temperature and moisture that can vary with time.

\subsubsection{MicExplicit}

As a first step we abstracted from fast dynamics of the assimilable pool, using the quasi-steady-state assumption. Specifically, we replaced the Monod uptake kinetics with the influx to the assimilable pool, i.e. the sum of decomposition fluxes.

\subsubsection{MicSteady}

As a second step we abstracted from the short-term dynamics of the active microbial biomass pool. We used the same equations as in the MicExplicit variant, but replaced active microbial biomass by its steady-state formulation, which depended on the current amount of substrates.

\subsubsection{LimUptake}

Further, we abstracted from several sources of respiration, keeping only an effective growth respiration in the system of equations. With this change the microbial efficiency, $\epsilon$, corresponded to the amount of uptake that is transformed to lower quality substrate, i.e. the humification coefficient $h$ in the original ICBM. Further, we lumped all microbial parameters into a single parameter $a_{\mathrm{A}}$. The limitation factor $l_{A}$ for decomposition could then be reformulated based on potential uptake. The potential uptake $u_{\text {Pot }}$ corresponded to the uptake with no microbial limitation, i.e. $l_{A}=1$, from all substrate qualities (here $Y$ and $O$ ).

$$
\begin{aligned}
& l_{A}=\max \left(0,1-\frac{a_{\mathrm{A}}}{u_{\mathrm{Pot}}}\right) \\
& u_{\mathrm{Pot}}=\epsilon \sum_{j} l_{\mathrm{e}, \mathrm{j}}(t) k_{j} S_{j}
\end{aligned}
$$

Note that Eq. (3) is not an ad hoc formulation but is derived from a simplification of the MicSteady model variant. However, it can also be seen as a representation of the substrate limitation strategy (Fig. 1). More details of Eq. (3) are discussed in Sect. 4.7. 


\subsubsection{LimFresh}

An alternate application of the substrate limitation strategy is to make decomposition depend on the high-quality $\mathrm{OM}$ only. Hence we implemented another abstraction, where we neglected the contribution of uptake from the low-quality organic matter in the formulation of the limitation factor.

\subsubsection{Independent}

This variant is equivalent to the original ICBM, where decomposition fluxes of SOM of different qualities are independent of each other. Here it is presented as a further abstraction of the LimUptake model variant where we fully neglected the substrate limitation in decomposition equations.

\subsection{Simulation scenarios}

The model variants presented in Sect. 2.1 have been applied to different scenarios of litter inputs. In all scenarios all model variants started from steady state for a litter input of $400 \mathrm{~g} \mathrm{C} \mathrm{m}^{-2} \mathrm{yr}^{-1}$. Parameters were derived from the following constraints: (1) prescribed initial carbon stocks in steady state before the change of litter input $-Y_{0}$ and $O_{0} ;$; (2) prescribed initial apparent substrate turnover times; (3) total microbial biomass of $2 \%$ of organic matter; and (4) prescribed initial activity of microbial biomass as expressed by the microbial limitation factor $l_{A}$. Initial microbial limitation factor was set to $5 \%$ for the LabPriming scenario, $20 \%$ for the FaceLim scenario and $80 \%$ for the other scenarios. The details of litter inputs over time and calculation of parameter values and initial stocks from the constraints above are given in Appendix B. As the scenarios explore consequences of different litter inputs, the environmental limitation factors were kept constant: $l_{e, Y}(t)=l_{e, O}(t)=0.8$.

\subsubsection{LabPriming}

Half of the accumulated yearly litter was added at once at the beginning and no litter was added thereafter. This emulates a laboratory priming experiment, where labelled fresh substrate is added at the beginning of a soil incubation and the label in the respiration flux is monitored over time without any further litter inputs.

\subsubsection{FaceAct}

Inputs increased by $25 \%$ and initial microbial biomass had a high activity (limitation factor of $80 \%$ ). This simulates a $\mathrm{CO}_{2}$ enrichment experiment (Norby et al., 2005). With this scenario litter input increased in the first year and stayed at this level thereafter.

\subsubsection{FaceLim}

Inputs increased by $25 \%$ and initial microbial biomass was energy-limited (limitation factor of $20 \%$ ) This is the same

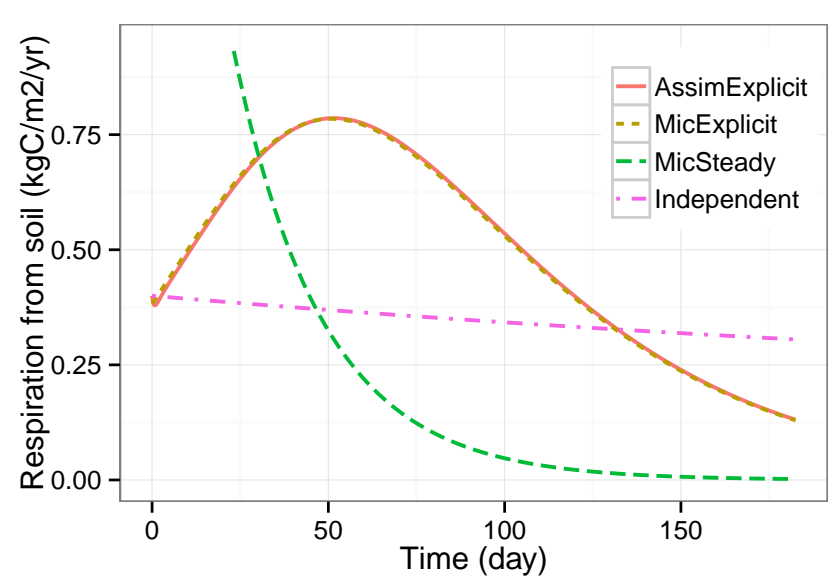

Fig. 3. Time series of respiration from autochthonous SOC, i.e. soil organic carbon present before substrate addition, in the LabPriming scenario.

as FaceAct scenario, except that initial microbial limitation factor was set to $20 \%$.

\subsubsection{DeadRoot}

Input decayed exponentially to $8 \mathrm{~g} \mathrm{Cm}^{2} \mathrm{yr}$. This simulates stabilization of organic matter based on the energy-limitation of the decomposers when the supply of high-quality organic matter diminishes. This may happen in the subsoil when the rooting system dies and fresh OM input is small because of absence of root exudates.

\section{Results of simulation studies}

In the course of this paper we discuss the effects of model simplifications and abstractions by comparing simulated trajectories to predictions of the more detailed model variants. Hence, we treat the predictions of the most detailed AssimExplicit model variant as the target to compare to.

\subsection{LabPriming scenario}

For the priming scenario, the time course of respiration from autochthonous soil carbon, i.e. soil organic carbon present before substrate addition, can be seen in Fig. 3. Respiration from autochthonous soil closely follows active microbial biomass (see electronic supplement PrimingMic.pdf). Both the AssimExplicit and the MicExplicit model variants show the typical hump-shaped pattern (e.g. Blagodatsky et al., 2010 , Fig 2b). The duration of the hump in this case is longer than in typical priming experiments, because the amendment is usually an easily available substrate that is degraded within hours to days. By contrast, we simulated addition of litter with a turnover time of one year. 


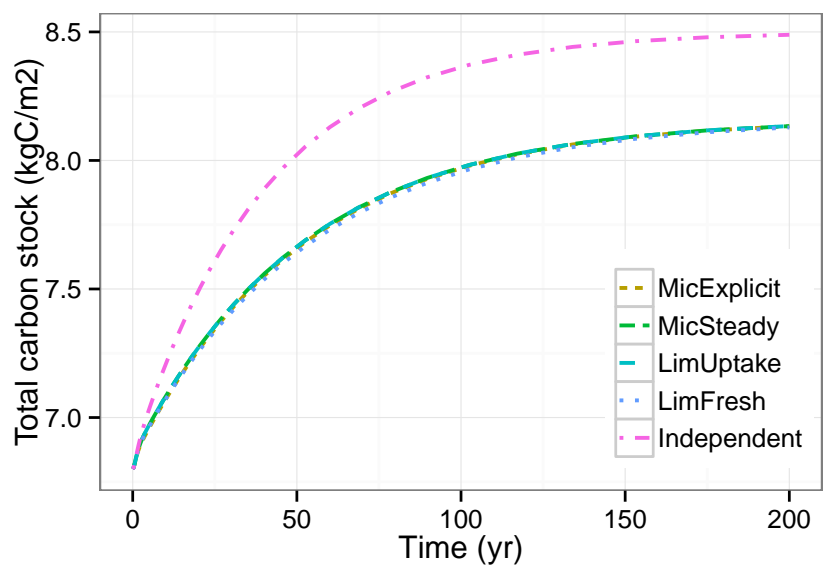

Fig. 4. Time series of total carbon stocks in the FaceAct scenario. Overplotting represents very close agreement.

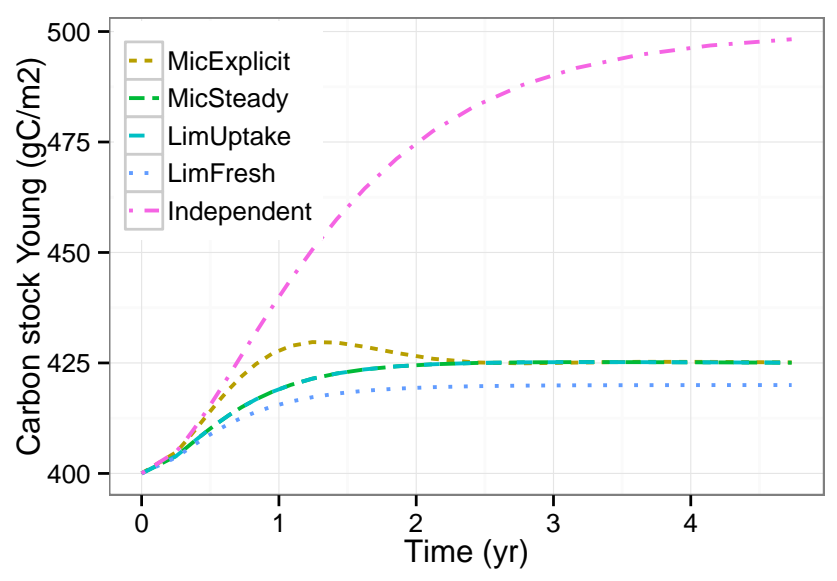

Fig. 5. Time series of carbon in the high-quality pool in the FaceLim scenario.

The AssimExplicit model predicted a very short (2 days) phase of negative priming, i.e. decreased respiration from autochthonous soil.

The MicExplicit model variant did not represent this negative priming effect. However, the overall dynamics at monthly timescale were described very well with the MicExplicit variant, despite abstracting from the dynamics of the assimilable pool.

The MicSteady model variant strongly overestimated the initial microbial biomass (see electronic supplement PrimingMic.pdf) and hence also the decomposition of the autochthonous SOM at the beginning of the incubation. Simulations of the LimUptake and LimFresh variants have not been conducted, as the abstraction level was already too high for this scenario.

There was no priming effect in the substrate independent model variant in which the autochthonous SOM decomposed independently from the added label.

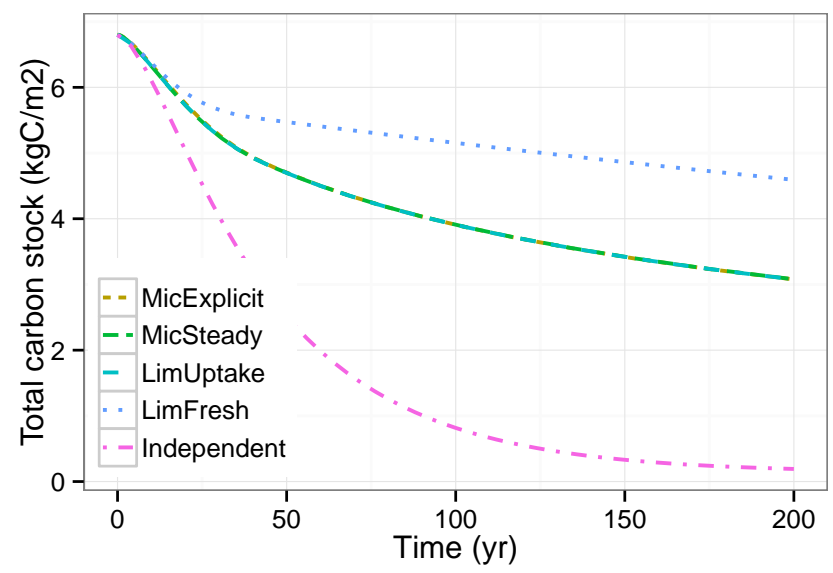

Fig. 6. Time series of total carbon stocks in the DeadRoot scenario.

\subsection{FaceAct and FaceLim scenarios}

At longer timescales, with continuous litter inputs that do not change abruptly, there was no discernible difference between predictions of the AssimExplicit and the MicExplicit model variants. There were also no discernible differences between predictions after 3 years of the MicExplicit and the MicSteady and LimUptake variants (Figs. 4-6).

All the variants of substrate interactions agreed remarkably well in the FaceAct scenario (Fig. 4). In contrast, the model in which substrates decompose independently predicted higher long-term carbon stocks. This difference became more pronounced when a more strongly substratelimited decomposer community was prescribed at the beginning of the incubation with the FaceLim scenario. All the models that accounted for substrate interactions predicted a smaller change in carbon stocks. This was because the increased litter input relieved the microbial limitation causing a faster SOM cycling.

In the first year after increasing litter inputs, the microbial activity was transiently smaller than its potential quasi-steady state. This effect was not represented with the more simplified model variant. The effect of this transition on predicted carbon dynamics, however, was so small that it was only seen when plotting the first years of the fast carbon stock (Fig. 5).

The slight deviation of the LimFresh variant from the more detailed variants was due to neglecting the uptake of lowquality organic matter as explained below.

\subsection{DeadRoot scenario}

In the DeadRoot simulation scenario (Fig. 6), the assimilation of low-quality organic matter became relevant. The highquality substrate was depleted fast, while the stored amounts of low-quality substrate were available for a longer time. Hence, the proportion of decomposition and uptake of the low-quality pool increased transiently. 
The LimFresh model variant, which was based solely on high-quality organic matter, predicted lower microbial activity and decomposition.

The substrate independent model did not account for the microbial energy-limitation at all and predicted a more rapid decomposition of the substrate.

\section{Discussion}

This study presents an approach of successively abstracting from detailed fast dynamics in complex models. It derives less complex formulations that still capture the important dynamics at a given timescale. Moreover, the derived lumped parameters can be traced back to the underlying more complex mechanisms.

The application of the model variants to various scenarios of changing litter input reveals pronounced differences in their dynamics. Distinct abstraction levels are appropriate at particular settings.

\subsection{Timescale}

The most important factor for choosing an appropriate abstraction level is timescale. When investigating the dynamics at longer scales, we assumed that the detailed description of the dynamics of fast processes can be replaced by an approximation based on a quasi-steady-state assumption (QSSA) (Segel and Slemrod, 1989). This is applicable where, after an initial fast transient period, the assimilable substrate and the microbial biomass can be regarded in steady state with respect to the instantaneous values of the available substrate.

The fast relaxation of the assimilable pool to steady state was caused by the fast uptake of substrate by microbes. The length of the transient period, where the assimilable pools differed from steady state (seen as difference between AssimExplicit and MicExplicit in Fig. 3) was of order of 1/(microbial growth rate). In this study, we assumed a maximum microbial growth rate of $1 /(24 \mathrm{~h})$. This is already a quite slow growth rate compared to priming experiments, where microbial communities respond to glucose with rates of about $1 /(5$ h) (Wutzler et al., 2012). Hence, we argue that the details of microbial uptake are not important at timescales longer than weeks.

The non-steady-state dynamics of microbial biomass are most important at the daily to monthly scale (Fig. 3) and are still visible over about two years (Fig. 5). With the MicExplicit model, decomposition of substrate is limited by the current activity, which is lagging behind its steady state. The timescale of this transient period is in the order of the turnover time of the changing substrate pool. Hence, the simplified models differed strongly from the microbial explicit model in the LabPriming scenario, which has studied monthly dynamics. Note, however, that in this study we used a turnover time of one year for the fastest pool, whereas a big part of the litter turns over faster. By using a shorter turnover time of the fast pool or a more fine-grained resolution of the substrate quality continuum (Ågren and Bosatta, 1996), we expect the differences between the model variants to be smaller.

When looking at decadal to centurial timescale with assuming continuous change of litter input, the quasi-steadystate assumption of microbial activity is a very effective model simplification compared to the more complex microbial explicit model variants (Figs. 4-6).

\subsection{Short-term environmental fluctuations}

An assumption of the used model simplifications is that substrate availability changes continuously. By contrast, substrate availability can change abruptly with fluctuations of environmental conditions. For example, a large amount of high-quality substrate can become available in a short time during rewetting events (Borken and Matzner, 2008). In these circumstances, as seen in Fig. 3, the simplified models overestimate initial microbial biomass and respiration and underestimate respiration at later times. They give wrong predictions for short timescale dynamics under these conditions. They are intended, however, for application at longer timescales. Hence, the more important problem is whether the errors average out or whether they will result in a bias in the mean rates on timescales from months to decades.

A thorough answer to this scaling question requires further study and discussion that is beyond the scope of this paper. However, we put forward the following hypothesis. There will be a consistent but negligibly small underestimation of mineralization with the microbial steady-state model. Our rationale in condensed form is as follows. The microbial dynamics in the explicit variant can be viewed as smoothed versions of the dynamics with the simplified variants. This is because the detailed variants let the actual microbial activity approach the extreme values more slowly than its quasi-steady state. Further, the mineralization is a monotonously increasing non-linear function of the active microbial biomass: $\operatorname{dec}=f\left(A /\left(m_{A}+A\right)\right)$. Hence, underestimation of actual microbial biomass leads to an underestimation of mineralization. Similarly, an overestimation of active microbial biomass leads to an overestimation of mineralization. The overestimation, however, will be consistently smaller than the underestimation, because the mineralization function is concave in $A$. Within the range of misrepresentation of microbial biomass, though, the deviation of the mineralization function from a linear function is very small. This is especially true, if active microbial biomass is much larger than its half-saturation constant $m_{A}$. Hence, we expect the bias to be small too. In addition, the effect may be counterbalanced by the observation that abrupt increases of substrate availability, e.g. with rewetting, occur more often than abrupt decreases of substrate availability. 


\subsection{Proportion of uptake from low-quality substrates}

Dynamics of microbial activity are usually dominated by the availability of high-quality substrate. This leads to the model simplification of only relating microbial activity or substrate limitation of decomposition to the availability of high-quality substrate (e.g. Guenet et al., 2012).

We argue that this simplification is only valid if the proportion of uptake from low-quality substrates compared to uptake from high-quality substrates is low.

The discussed simplification is represented by the LimFresh model variant. It predicts similar dynamics as the slightly more detailed LimUptake variant in all scenarios of high litter inputs. However, predictions for the DeadRoot scenario of diminished litter inputs (Fig. 6) differ considerably. This is because the high-quality OM is consumed and depleted faster than the low-quality OM. Hence, under such conditions, the proportion of low-quality OM to microbial uptake is so high that it cannot be neglected.

This scenario demonstrates the importance of distinguishing between hot spots, sites of low input of high-quality OM, and the transitions between them. For further model development, we propose to first start accounting for the vertical heterogeneity of the inputs: high in top soil and low at most sites in subsoil (Braakhekke et al., 2013).

\subsection{OM stabilization by energy limitation}

In the DeadRoot scenario, the long-term predictions of the model with substrate interactions differ notably from the predictions of the model with independent substrate decomposition. This is because the substrate interactions can explain OM stabilization by energy limitation of decomposers (Fontaine et al., 2007). With decreasing supply of high-quality substrate (young pool in the ICBM), the microbial limitation to decomposition increases. This results in a turnover acceleration of the low-quality substrate (Fig. 7).

In addition, this mechanism also provides an alternative explanation of the observed deceleration of decomposition at long-term bare fallow experiments (e.g. Barré et al., 2010, Fig. 1). Traditionally, additional very slowly decaying OM pools have been included in the SOM models (McGill, 1996) to explain those patterns. However, recent studies have shown that the old OM associated with these pools is vulnerable to priming effects (Fontaine et al., 2007). Hence, the emerging view is that the observed long turnover times are properties of the environment instead of being associated with the conceptual OM pools (Schmidt et al., 2011). This is in line with the predictions of those model variants in this study that included substrate interactions.

While the traditional substrate independent models are quite successful in explaining effects of changing litter inputs under one land use at one site, they often need to be re-parametrized to other sites. Moreover, data on forestgrassland transition could be modelled much better with a

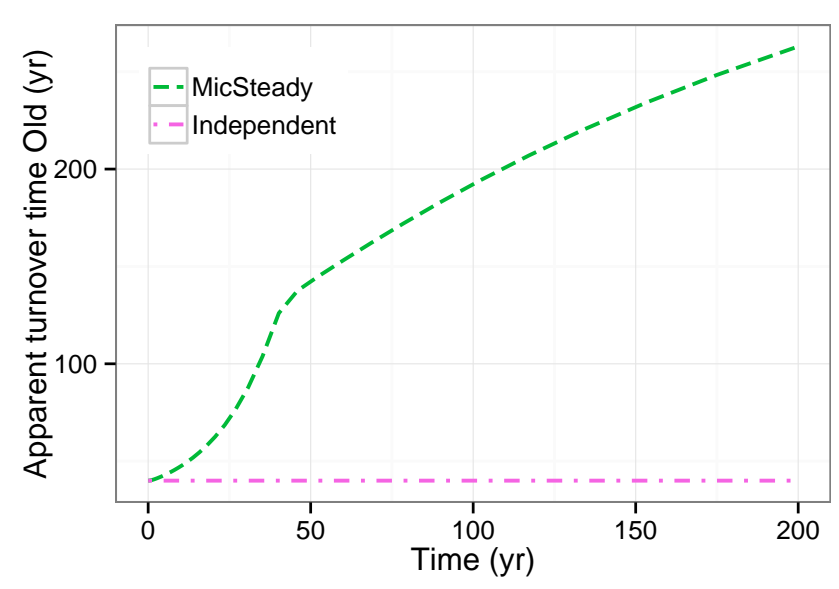

Fig. 7. Increase of apparent turnover time $1 / k_{\text {app, Old }}=1 /\left(l_{A} k_{\text {Old }}\right)$ in the DeadRoot scenario.

redistribution of carbon between different SOM-qualities after the disturbance instead of modifying model parameters (Gottschalk et al., 2010). It will be interesting to test if changed substrate interactions can better explain such data.

\subsection{Acceleration of SOM turnover instead of SOM accumulation}

A second major difference in dynamics with regard to substrate interactions was seen in the FaceLim simulation scenario (Fig. 5). With the substrate independent model, a $25 \%$ increase of the input led to $25 \%$ increase of the total OM stock. By contrast, the substrate interaction models predicted a release of microbial limitation. This led to an accelerated decomposition, which resulted in only a slight increase in OM stocks. This prediction is in line with several observations from Free Air Carbon Enrichment (FACE) experiments (Cardon et al., 2001; Carney et al., 2007; Heath et al., 2005; Trueman and Gonzalez-Meler, 2005). These studies observe that an increased net primary productivity and rhizodeposition, especially with nitrogen limitation (Norby et al., 2010; Phillips et al., 2011), is often not accompanied by a corresponding increase in soil carbon stocks (Drake et al., 2011).

\subsection{Microbial activity}

The more complex model variants make use of a pool called the active microbial biomass. Here we discuss why we use this concept instead of soil microbial biomass.

Aside from hot spots of high-quality OM, most of the microbes are found in a sustaining state (Panikov, 1995). This state is characterized by low energy requirements, i.e. maintenance respiration, but also reduced growth and metabolic rates. When substrate availability increases, large parts of the metabolic machinery need to be synthesized before growth can take place. This causes a time lag before exponential 


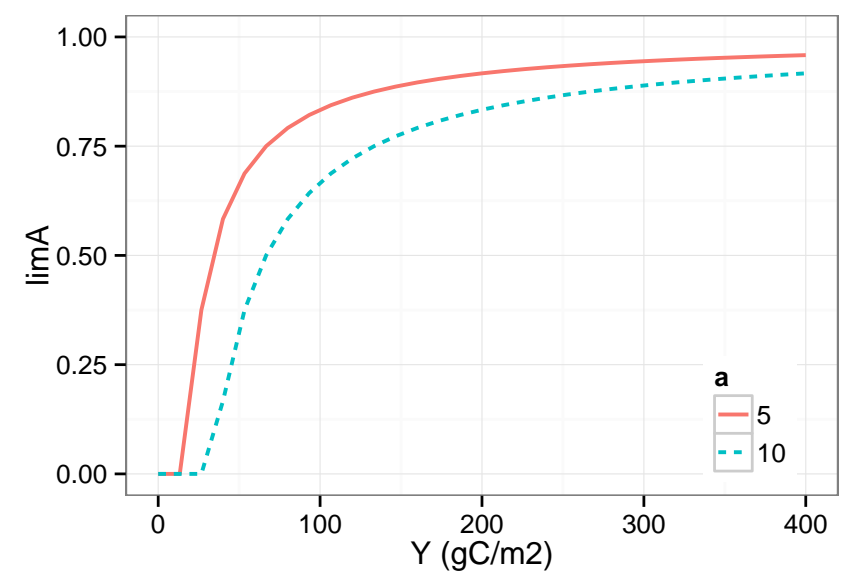

Fig. 8. Microbial limitation $l_{A}$ as a function of amount of a single substrate $Y: l_{A}=\max \left(0,1-\frac{a_{\mathrm{A}}}{\epsilon l_{\mathrm{e}, \mathrm{Y}} k_{Y} Y}\right)$. With $\epsilon=0.3, l_{\mathrm{e}, \mathrm{Y}}=1$, and $k_{Y}=1 \mathrm{yr}^{-1}$.

growth occurs. The observed time lag can be related to the activity state. Hence, amongst all the methods of measuring soil microbial biomass, the kinetic respiration analysis (Panikov and Sizova, 1996; Blagodatsky et al., 2000; Wutzler et al., 2012) might come closest to the modelled pool of active microbial biomass.

In addition to overall activity, the community structure and competition presumably play major roles in regulating $\mathrm{OM}$ cycling (Fontaine et al., 2003; Treseder et al., 2011; ToddBrown et al., 2012). Such community effects were not considered even with the most detailed model in the current study.

At low growth rates, other factors related to the microbial energy budget in addition to microbial substrate use efficiency become important. On reason is maintenance respiration, which is required also with low or no uptake of substrate (Pirt, 1965; Beeftink et al., 1990; van Bodegom, 2007). Other not considered here but potentially influential factors are dynamics of predation (Raynaud et al., 2006), limitation by resources other than carbon (Fontaine and Barot, 2005), preferential substrate usage (Blagodatskaya and Kuzyakov, 2008), and adaptation (Schmidt et al., 2007).

Further studies can start from models of more complex microbial interactions and use the presented approach of successively abstracting from the details.

\subsection{Microbial limitation factor}

Results show that the abstraction level in the LimUptake model variant is able to account for the effects of microbial activity at timescales of seasons to decades. Therefore, we discuss the derived one-parameter Eq. (3) in more detail.

For a single substrate pool, the equation is plotted in Fig. 8. Parameter $a_{A}$ corresponds to the minimum carbon uptake flux that can support active microbial biomass. Below this threshold, the microbial community has more carbon costs in sustaining growing compartments than what can be obtained from degrading the substrate. With larger concentrations of available substrate, the investments in synthesizing enzymes yield higher returns. Hence, with more and more available substrate, a bigger part of the community can be active.

Note that the decomposition and uptake flux also depend on current environmental conditions $\left(l_{e}\right)$ and the substrate limitation factor fluctuates with environmental drivers.

\subsection{Priming effects}

The AssimExplicit model variant simulates a short phase of negative priming in the LabPriming scenario. This is in line with the hypothesis that microbial dynamics cause the priming effect (Blagodatskaya and Kuzyakov, 2008). However, while negative priming is usually attributed to preferential substrate usage, in this model it is solely caused by a dilution of the assimilable pool with the carbon from the amendment. Right after the amendment, microbes take up and respire the same total amount of carbon as before, but a part of it originates from the amendment instead of the autochthonous soil carbon.

There is a discussion about apparent and real priming effects (e.g. see review by Blagodatskaya and Kuzyakov, 2008). The priming effect is defined as the increased or diminished mineralization of soil organic matter after treating soil with an amendment, compared to a control without amendment (Kuzyakov et al., 2000). Apparent priming is an increased respiration originating from increased turnover of microbial biomass without additional mineralization of soil organic matter (Blagodatskaya and Kuzyakov, 2008). We argue that the distinction between apparent and real priming is not as important on longer timescales as on the short term. Microbial biomass is usually only a small fraction of 2-4\% (Anderson and Domsch, 1989) of organic matter. The active part can again be an order of magnitude smaller (Wutzler et al., 2012). Hence, the turnover of one complete pool of active microbial biomass contributes only a small part to respiration integrated over seasons and years. If we detect significant priming effects over this timescale, the contribution of primed carbon originating from initially present microbial biomass will be small compared to the overall effect.

\subsection{Outlook}

In order to highlight the energy limitation aspects, this study focused on SOM cycling under constant environmental conditions and no other limitations than carbon substrate. In order to gain a more comprehensive understanding of substrate interactions and to compare model predictions to observations, other aspects need to be considered as well. First, due to the narrow range in the stoichiometry of microbial biomass, substrate interactions will be strongly determined 
by differences in elemental composition of litter and transformed soil organic matter (Fontaine et al., 2003). Second, substrate interactions can influence the temperature sensitivity of decomposition (Thiessen et al., 2012). Third, the availability of substrate and oxygen is strongly influenced by soil moisture (Davidson et al., 2012). And, fourth, we discussed several aspects of microbial dynamics such as preferential substrate usage and predation, which are not considered in this study.

Further simulation experiments should be designed to study whether the bias introduced by the quasi-steady-state assumption with rapidly changing environmental conditions is indeed negligible.

A bottom-up strategy of successively integrating effects of microbial dynamics into lumped models is the following. First set up more detailed models that include refined processes and compare model predictions to data of short-term experiments. The detailed models can then be simplified similarly as it has been done with the assimilable and microbial explicit ICBM of this study.

A complementary strategy is to implement several forms of substrate interactions such as Eq. (3) directly into lumped SOM cycling models that already account for stoichiometry and environmental constraints. Model predictions can be compared to data from FACE experiments or long-term experiments of changes in $\mathrm{C} 3 / \mathrm{C} 4$ vegetation, or long-term observation of carbon stocks and fluxes at specific sites (Smith et al., 1996).

\section{Conclusions}

There are several basic strategies of incorporating interactions of SOM qualities into SOM cycling models. Different abstraction levels are appropriate at different timescales and different magnitudes of changes in litter input. The substrate interaction strategy is appropriate at decadal scale application. Out of the five model variants presented in this paper, the LimUptake variant is more parsimonious than the LimFresh variant. It has only one additional parameter but includes more microbial detail. By contrast, the strategy of explicitly representing microbial dynamics (MicExplicit variant) is appropriate for applications involving fast changes in litter inputs where the transient microbial dynamics and details of microbial energy budget become important.

The derived simple one-parameter equation of microbial limitation Eq. (3) can be directly transferred to other SOM cycling models. Incorporating substrate interactions into SOM models, as exemplified by the current study, results in qualitatively different dynamics both on the short as well as on the long timescale.
Substrate interactions offer an explanation for the acceleration of SOM cycling instead of extensive SOM accumulation as observed in several FACE experiments. They offer an alternative explanation of the deceleration of decomposition with time in bare fallow long-term experiments compared to the explanation of a continuing decrease of substrate quality. Integration of perspective with other aspects of SOM cycling such as other nutrients and environmental influences requires further work both on short-term controlled experiments as well as model data integration with long-term datasets. Overall, substrate interactions help us to understand and quantitatively model SOM dynamics and stabilization.

\section{Appendix A}

\section{ICBM variants}

This appendix describes the model abstraction process in more detail and reports the differential equations used in the variants of the ICBM. State variables and parameters are explained in Table 1.

\section{A1 AssimExplicit}

We started with a detailed assimilable and microbial explicit model similar to several published ones (Blagodatsky and Richter, 1998; Schimel and Weintraub, 2003; Blagodatsky et al., 2010). Carbon input flux $i$ enters the highquality pool $Y$. Microbial uptake of assimilable substrate was modelled by Monod kinetics (Monod, 1949; Madigan and Martinko, 2006). Decomposition of non-assimilable substrate was modelled by an equation that was first order to substrate but was a saturating function with active microbial biomass (Schimel and Weintraub, 2003; Wutzler and Reichstein, 2008). This represented the declining probability of enzyme substrate encounters with decreasing concentration of active microbial biomass. As a first approximation we assumed that all microbial turnover is added to the low-quality pool. Microbial turnover was modelled first order to active microbial biomass.

Environmental limitations $l_{\mathrm{e}, \mathrm{S}}$ of decomposition by cold or drought are treated here as externally computed model drivers that can change with time. 


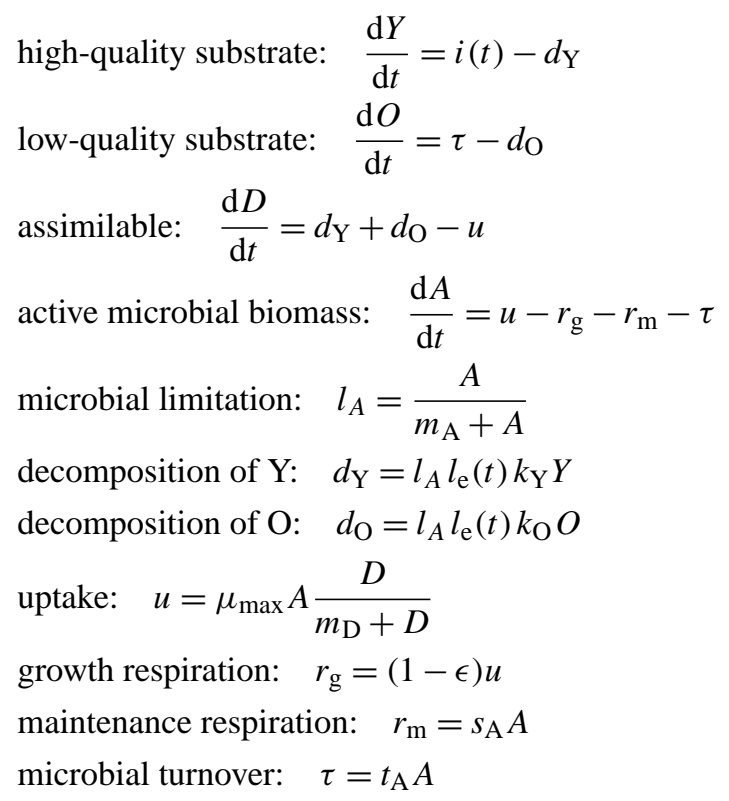

\section{A2 MicExplicit}

First, we abstracted from the fast dynamics of the assimilable pool. Near its quasi-steady state, the change of the pool is small compared to its inflow and outflow. Hence we modelled the microbial uptake as the sum of the inputs to this pool, i.e. the sum over all decomposition fluxes. The equations are the same as in the AssimExplicit variant, except for the uptake $u$.

uptake: $u=d_{\mathrm{Y}}+d_{\mathrm{O}}$

\section{A3 MicSteady}

Second, we abstracted from the fast dynamics of the active microbial biomass. Again we made use of the quasi-steadystate approximation. Equations were the same as in the MicExplicit variant, unless microbial biomass $A$ was replaced by its quasi-steady state $A^{*}$ in all equations.

Quasi-steady state of active microbial biomass $A^{*}$ was derived by setting the derivative to time to zero.

$$
\begin{aligned}
& \frac{\mathrm{dA}^{*}}{\mathrm{~d} t}=u-r_{\mathrm{g}}-r_{\mathrm{m}}-\tau=0 \\
& A^{*}=\max \left(0, \frac{\epsilon\left(l_{\mathrm{e}, \mathrm{Y}}(t) k_{\mathrm{Y}} Y+l_{\mathrm{e}, \mathrm{O}}(t) k_{\mathrm{O}} O\right)}{s_{\mathrm{A}}+t_{\mathrm{A}}}-m_{\mathrm{A}}\right)
\end{aligned}
$$

By substituting the steady-state biomass $A^{*}$ into the other equations, we could express them directly as a function of microbial parameters. For example, for the microbial limitation we derived the following equation.

$l_{A}=\max \left(0,1-\frac{m_{\mathrm{A}}\left(s_{\mathrm{A}}+t_{\mathrm{A}}\right)}{\epsilon\left(l_{\mathrm{e}, \mathrm{Y}}(t) k_{\mathrm{Y}} Y+l_{\mathrm{e}, \mathrm{O}}(t) k_{\mathrm{O}} O\right)}\right)$

\section{A4 LimUptake}

We further abstracted from different kinds of respiration and assumed that respiration could be expressed solely by the microbial efficiency $\epsilon$. This corresponds to including maintenance respiration into an effective growth respiration term.

By lumping the microbial parameters into an effective parameter $a_{A}$, we reformulated the microbial limitation. This resulted in an expression that was dependent on a minimum potential uptake, rendering microbial mechanisms completely implicit. Decomposition $d_{\mathrm{Y}}$ and $d_{\mathrm{O}}$ were the same as in the AssimExplicit variant.

substrate Young: $\frac{\mathrm{d} Y}{\mathrm{~d} t}=i-d_{\mathrm{Y}}$

substrate Old: $\frac{\mathrm{d} O}{\mathrm{~d} t}=\epsilon\left(d_{\mathrm{Y}}+d_{\mathrm{O}}\right)-d_{\mathrm{O}}$

respiration: $\quad r=(1-\epsilon)\left(d_{\mathrm{Y}}+d_{\mathrm{O}}\right)$

lumped biomass parameter: $a_{\mathrm{A}}=m_{\mathrm{A}}\left(s_{\mathrm{A}}+t_{\mathrm{A}}\right)$

uptake limitation $: l_{A}=$

$$
\max \left(0,1-\frac{a_{\mathrm{A}}}{\epsilon\left(l_{\mathrm{e}, \mathrm{Y}}(t) k_{\mathrm{Y}} Y+l_{\mathrm{e}, \mathrm{O}}(t) k_{\mathrm{O}} O\right)}\right)
$$

\section{A5 LimFresh}

Usually, the uptake of high-quality substrate (here $Y$ ) is much larger than the uptake of low-quality substrate (here $O$ ). Hence, we further explored the simplified model variant that neglected the uptake of low-quality substrate in the limitation factor $l_{A}$. All other equations were the same as in the LimUptake variant.

uptake limitation: $\quad l_{A}=\max \left(0,1-\frac{a_{\mathrm{A}}}{\epsilon l_{\mathrm{e}, \mathrm{Y}}(t) k_{\mathrm{Y}} Y}\right)$

\section{A6 Independent}

Finally we abstracted the model by neglecting substrate limitations at all and omitted the limitation factor in the decomposition equations. All other equations were the same as in the LimUptake variant. Decomposition fluxes of the substrate qualities were independent of each other.

decomposition of $\mathrm{Y}: \quad d_{\mathrm{Y}}=l_{\mathrm{e}, \mathrm{Y}}(t) k_{\mathrm{Y}} Y$

decomposition of $\mathrm{O}: \quad d_{\mathrm{O}}=l_{\mathrm{e}, \mathrm{O}}(t) k_{\mathrm{O}} O$

By this we derived a model structure that was equivalent to the original ICBM model. The microbial efficiency $\epsilon$ structurally corresponded to the humification factor $h$ in the original model. Note, however, that its interpretations differ in terms of what the low-quality matter is composed of - microbial turnover versus preserved litter. Similarly, the decomposition rate $k_{\mathrm{O}}^{\prime}$ in the original model did not take into account recycling of decomposed low-quality OM by microbial turnover. It relates to the one in this model by $k_{\mathrm{O}}^{\prime}=(1-\epsilon) k_{\mathrm{O}}$. 


\section{Appendix B}

\section{Model parameterization}

This appendix reports the calculation of parameters used in running the simulation scenarios in Sect. 2.2. Parameters were chosen so that all variants predicted the same steady-state carbon stocks before the change of litter input: $Y_{0}=400 \mathrm{~g} \mathrm{C} \mathrm{m}^{-2}, O_{0}=6400 \mathrm{~g} \mathrm{Cm}^{-2}$. All apparent turnover times corresponded to 1 and $40 \mathrm{yr}$ for the $Y$ and $O$ pool respectively. Other model parameters were derived from these constrained apparent turnover rates, the steady-state assumptions, and other reasonable constraints, e.g. that total microbial biomass was $2 \%$ of organic matter.

\section{B1 LabPriming}

The amount of amendment was on the order of soil microbial biomass: $2 \% \mathrm{C}_{\mathrm{Tot}} \approx 140 \mathrm{~g} \mathrm{~m}^{-2}$ (Blagodatskaya and Kuzyakov, 2008).

Input: $i(t \geq 0)=0 \mathrm{~g} \mathrm{~m}^{-2} \mathrm{yr}^{-1}$

Average input before the experiment: $i_{0}=400 \mathrm{~g} \mathrm{~m}^{-2} \mathrm{yr}^{-1}$ Added label at $t=0: Y_{\text {label }}=\frac{1}{2} i_{0} 1 \mathrm{yr}=200 \mathrm{~g} \mathrm{~m}^{-2}$

\section{B1.1 Independent}

Initial apparent decomposition rates:

$$
\begin{aligned}
& -k_{\mathrm{Y}, \mathrm{app}}=l_{\mathrm{e}, \mathrm{Y}}(0) k_{\mathrm{Y}}=\frac{1}{1 \mathrm{yr}} \\
& -k_{\mathrm{O}, \mathrm{app}}=l_{\mathrm{e}, \mathrm{O}}(0) k_{\mathrm{O}}=\frac{1}{40 \mathrm{yr}}
\end{aligned}
$$

Dividing the apparent decomposition rates by the mean environmental limitation $l_{\mathrm{e}, \mathrm{j}}$ resulted in decomposition rates.

Microbial efficiency is $\epsilon=0.4$. Initial pools then result from steady state:

$$
\begin{aligned}
& -Y_{0}=\frac{i_{0}}{k_{\mathrm{Y}, \mathrm{app}}}, \\
& -O_{0}=\frac{\epsilon i_{0}}{k_{\text {O,app }}} .
\end{aligned}
$$

\section{B1.2 MicExplicit and MicSteady}

Apparent decomposition rates, and microbial efficiency, and calculation of initial pools were the same as with the independent model variant.

Initial microbial limitation was set to $l_{A}(0)=0.05$ corresponding to low activity due to some time of storage before the experiment.

Dividing the apparent decomposition rates by $\left(l_{0} l_{\mathrm{e}, \mathrm{j}}\right)$ resulted in decomposition rates $k_{\mathrm{Y}}$ and $k_{\mathrm{O}}$.

Given an initial active microbial biomass $A_{0}=0.02\left(Y_{0}+\right.$ $\left.O_{0}\right) l_{0}$, the other rates were defined by the initial steady-state condition:

$$
\begin{aligned}
& \text { Affinity: } m_{\mathrm{a}}=A_{0}\left(\frac{1}{l_{\mathrm{A}}(0)}-1\right), \\
& \text { Microbial turnover rate: } t_{\mathrm{A}}=\frac{l_{\mathrm{A}}(0) l_{\mathrm{e}, \mathrm{O}}(0) k_{\mathrm{O}_{0}} O}{A_{0}}, \\
& \text { Maintenance rate: } \frac{\epsilon l_{\mathrm{A}}(0)\left(l_{\mathrm{e}, \mathrm{Y}}(0) k_{\mathrm{Y}} Y_{0}+l_{\mathrm{e}, \mathrm{O}}(0) k_{\mathrm{O}} O_{0}\right)}{A_{0}}-t_{\mathrm{A}} .
\end{aligned}
$$

\section{B1.3 AssimExplicit}

Same as MicExplicit variant. In addition maximum growth rate was set to $\mu_{\max }=1 /(24 \mathrm{~h})$. Typical maximum growth rates in priming experiments are higher than $1 /$ day (Wutzler et al., 2012) but correspond to communities growing on substrates that are mineralized faster. With higher growth rates, microbial dynamics would be even faster near steady state.

Initial assimilable pools were set to $D_{0}=1 \mathrm{~g} \mathrm{~m}^{-} 2$, which corresponds to $10 \mathrm{mgl}^{-1}$ (Borken et al., 2011) for a $40 \mathrm{~cm}$ deep soil and $25 \%$ of the volume occupied by water. Halfsaturation $m_{S}$ was calculated from steady-state assumption of the assimilate pool prior to change of litter inputs as $m_{S}=$ $D_{0}\left(\frac{\mu_{\max } A_{0}}{l_{\mathrm{A}}(0)\left(l_{\mathrm{e}, \mathrm{Y}}(0) k_{\mathrm{Y}} Y_{0}+l_{\mathrm{e}, \mathrm{O}}(0) k_{\mathrm{O}} O_{0}\right)}-1\right)$.

\section{B2 FaceAct}

Soil carbon input increased from steady-state values of $i_{0}=$ $400 \mathrm{~g} \mathrm{C} \mathrm{m}^{-2} \mathrm{yr}^{-1}$ rapidly $\left(e_{\text {Fold }}=0.5 \mathrm{yr}\right)$ levelling out at $r=$ $25 \%$ above $i_{0}$ (Phillips et al., 2011).

$i(t)=i_{0}+r i_{0}\left(1-\exp \left(-1 / e_{\text {Fold }} t\right)\right)$

Parameters for independent, MicExplicit, and MicSteady variants were the same as with the LabPriming scenario, unless initial microbial limitation was set to $l_{0}=0.8$ assuming high microbial activity adapted to high-quality inputs from rhizodeposition.

The LimUptake and the LimFresh model variant neglected maintenance respiration. In order to match the same initial total stocks, the growth respiration had to compensate for this. Hence the effective microbial efficiency was set to 0.7143 times the true $\epsilon$.

The lumped limitation parameters of the LimUptake and the LimFresh variants were calculated from steady-state assumption before the change of litter input: $a_{\mathrm{A}}=(1-$ $\left.l_{\mathrm{A}}(0)\right) \epsilon\left(l_{\mathrm{e}, \mathrm{Y}}(0) k_{\mathrm{Y}} Y_{0}+l_{\mathrm{e}, \mathrm{O}}(0) k_{\mathrm{O}} O_{0}\right)$.

\section{B3 FaceLim}

This scenario was the same as the FaceAct scenario, unless initial microbial limitation was set to $l_{A}(0)=0.2$

\section{B4 DeadRoot}

Input decreased from steady-state values of $i_{0}=$ $400 \mathrm{~g} \mathrm{Cm}^{-2} \mathrm{yr}^{-1}$ slowly $\left(e_{\text {Fold }}=10 \mathrm{yr}\right)$ to a minimum arbitrary low value of $i_{\min }=i_{0} / 50$. The timescale was chosen to match a decomposing coarse root.

$i(t)=\max \left(i_{\min }, i_{0} \exp \left(-1 / e_{\text {Fold }} t\right)\right.$

Parameters were calculated the same way as in the FaceAct scenario. 
Acknowledgements. This work was supported by the ERC starting grant QUASOM (ERC-2007-StG-208516). We thank B. Guenet, another anonymous reviewer, and colleagues S. Zähle, C. Sierra, B. Ahrens and M. Braakhekke for valuable comments on the manuscript.

The service charges for this open access publication have been covered by the Max Planck Society.

Edited by: P. Stoy

\section{References}

Ågren, G. and Bosatta, E.: Theoretical ecosystem ecology - Understanding element cycles, Cambridge University Press, Cambridge, 1996.

Allison, S., Wallenstein, M., and Bradford, M.: Soil-carbon response to warming dependent on microbial physiology, Nature Geoscience, 3, 336-340, 2010.

Anderson, T.-H. and Domsch, K.: Ratios of microbial biomass carbon to total organic carbon in arable soils, Soil Biol. Biochem., 21, 471-479, doi:10.1016/0038-0717(89)90117-X, 1989.

Andrén, O. and Kätterer, T.: ICBM: The introductory carbon balance model for exploration of soil carbon balances, Ecological Applications, 7, 1226-1236, 1997

Barré, P., Eglin, T., Christensen, B. T., Ciais, P., Houot, S., Kätterer, T., van Oort, F., Peylin, P., Poulton, P. R., Romanenkov, V., and Chenu, C.: Quantifying and isolating stable soil organic carbon using long-term bare fallow experiments, Biogeosciences, 7, 3839-3850, doi:10.5194/bg-7-3839-2010, 2010.

Beeftink, H. H., Vanderheijden, R. T. J. M., and Heijnen, J. J.: Maintenance Requirements - Energy Supply From Simultaneous Endogenous Respiration And Substrate Consumption, Fems Microb. Ecol., 73, 203-209, 1990.

Blagodatskaya, E. and Kuzyakov, Y.: Mechanisms of real and apparent priming effects and their dependence on soil microbial biomass and community structure: critical review, Biol. Fert. Soils, 45, 115-131, doi:10.1007/s00374-008-0334-y, 2008.

Blagodatsky, S., Blagodatskaya, E., Yuyukina, T., and Kuzyakov, Y.: Model of apparent and real priming effects: Linking microbial activity with soil organic matter decomposition, Soil Biol. Biochem., 42, 1275-1283, doi:10.1016/j.soilbio.2010.04.005, 2010.

Blagodatsky, S. A. and Richter, O.: Microbial growth in soil and nitrogen turnover: A theoretical model considering the activity state of microorganisms, Soil Biol. Biochem., 30, 1743-1755, 1998.

Blagodatsky, S. A., Heinemeyer, O., and Richter, J.: Estimating the active and total soil microbial biomass by kinetic respiration analysis, Biol. Fert. Soils, 32, 73-81, 2000.

Borken, W. and Matzner, E.: Reappraisal of drying and wetting effects on $\mathrm{C}$ and $\mathrm{N}$ mineralization and fluxes in soils, Glob. Change Biol., 15, 808-824, doi:10.1111/j.13652486.2008.01681.x, 2008.

Borken, W., Ahrens, B., Schulz, C., and Zimmermann, L.: Site-tosite variability and temporal trends of DOC concentrations and fluxes in temperate forest soils, Glob. Change Biol., 17, 24282443, doi:10.1111/j.1365-2486.2011.02390.x, 2011.
Braakhekke, M. C., Wutzler, T., Beer, C., Kattge, J., Schrumpf, M., Ahrens, B., Schöning, I., Hoosbeek, M. R., Kruijt, B., Kabat, P., and Reichstein, M.: Modeling the vertical soil organic matter profile using Bayesian parameter estimation, Biogeosciences, 10 399-420, doi:10.5194/bg-10-399-2013, 2013.

Cardon, Z. G., Hungate, B. A., Cambardella, C. A., ChapinIII, F. S., Field, C. B., Holland, E. A., and Mooney, H. A.: Contrasting effects of elevated $\mathrm{CO}_{2}$ on old and new soil carbon pools, Soil Biol. Biochem., 33, 365-373, 2001.

Carney, K. M., Hungate, B. A., Drake, B. G., and Megonigal, J. P.: Altered soil microbial community at elevated $\mathrm{CO}_{2}$ leads to loss of soil carbon, P. Natl. A. Sci., 104, 4990-4995, doi:10.1073/pnas.0610045104, 2007.

Davidson, E. A., Samanta, S., Caramori, S. S., and Savage, K. E.: The Dual Arrhenius and Michaelis-Menten (DAMM) kinetics model for decomposition of soil organic matter at hourly to seasonal time scales, Glob. Change Biol., doi:10.1111/j.13652486.2011.02546.x, 2012.

Drake, J. E., Gallet-Budynek, A., Hofmockel, K. S., Bernhardt, E. S., Billings, S. A., Jackson, R. B., Johnsen, K. S., Lichter, J., McCarthy, H. R., McCormack, M. L., Moore, D. J. P., Oren, R., Palmroth, S., Phillips, R. P., Pippen, J. S., Pritchard, S. G., Treseder, K. K., Schlesinger, W. H., DeLucia, E. H., and Finzi, A. C.: Increases in the flux of carbon belowground stimulate nitrogen uptake and sustain the long-term enhancement of forest productivity under elevated $\mathrm{CO}_{2}$, Ecol. Lett., 14, 349-357, doi:10.1111/j.1461-0248.2011.01593.x, 2011.

Fang, C., Smith, P., Smith, J. U., and Moncrieff, J. B.: Incorporating microorganisms as decomposers into models to simulate soil organic matter decomposition, Geoderma, 129, 139-146, 2005.

Fontaine, S. and Barot, S.: Size and functional diversity of microbe populations control plant persistence and long-term soil carbon accumulation, Ecol. Lett., 8, 1075-1087, 2005.

Fontaine, S., Mariotti, A., and Abbadie, L.: The priming effect of organic matter: a question of microbial competition?, Soil Biol. Biochem., 35, 837-843, 2003.

Fontaine, S., Barot, S., Barré, P., Bdioui, N., Mary, B., and Rumpel, C.: Stability of organic carbon in deep soil layers controlled by fresh carbon supply, Nature, 450, 277-281, 2007.

Gottschalk, P., Bellarby, J., Chenu, C., Foereid, B., Smith, P., Wattenbach, M., Zingore, S., and Smith, J.: Simulation of soil organic carbon response at forest cultivation sequences using $13 \mathrm{C}$ measurements, Org. Geochem., 41, 41-54, 2010.

Guenet, B., Danger, M., Abbadie, L., and Lacroix, G.: Priming effect: bridging the gap between terrestrial and aquatic ecology, Ecology, 91, 2850-2861, doi:10.1890/09-1968.1, 2010.

Guenet, B., Eglin, T., Vasilyeva, N., Peylin, P., Ciais, P., and Chenu, C.: The relative importance of decomposition and transport mechanisms in accounting for $\mathrm{C}$ profiles, Biogeosciences Discuss., 9, 14145-14173, doi:10.5194/bgd-9-14145-2012, 2012.

Heath, J., Ayres, E., Possell, M., Bardgett, R. D., Black, H. I. J., Grant, H., Ineson, P., and Kerstiens, G.: Rising atmospheric $\mathrm{CO}_{2}$ reduces sequestration of root-derived soil carbon, Science, 309, 1711-1713, 2005.

Hilborn, R. and Mangel, M.: The ecological detective. confronting models with data, Princeton Univesity Press, Princeton, NJ., 1997.

Jenkinson, D., Fox, R., and Rayner, J.: Interactions between fertilizer nitrogen and soil nitrogen-the so-called "prim- 
ing" effect, J. Soil Sci., 36, 425-444, doi:10.1111/j.13652389.1985.tb00348.x, 1985.

Jenkinson, D. S. and Coleman, K.: The turnover of organic carbon in subsoils, Part 2, Modelling carbon turnover, Europ. J. Soil Sci., 59, 400-413, doi:10.1111/j.1365-2389.2008.01026.x, 2008.

Jobbagy, E. G. and Jackson, R. B.: The vertical distribution of soil organic carbon and its relation to climate and vegetation, Ecol. Appl., 10, 423-436, 2000.

Kuzyakov, Y., Friedel, J. K., and Stahr, K.: Review of mechanisms and quantification of priming effects, Soil Biol. Biochem., 32, 1485-1498, 2000.

Liski, J., Palosuo, T., Peltoniemi, M., and Sievanen, R.: Carbon and decomposition model Yasso for forest soils, Ecol. Modell., 189, 168-182, 2005.

Löhnis, F.: Nitrogen availability of green manures, Soil Sci., 22, 253-290, 1926.

Madigan, M. and Martinko, J.: Brock Biology Of Microorganisms 11 Edn., Prentice Hall, 11 Edn., 2006.

Manzoni, S. and Porporato, A.: Soil carbon and nitrogen mineralization: Theory and models across scales, Soil Biol. Biochem., 41, 1355-1379, doi:10.1016/j.soilbio.2009.02.031, 2009.

McGill, W. B.: Review and classification of ten soil organic matter (SOM) models, in: Evaluation of soil organic matter models using existing, long-term datasets, edited by: Powlson, D. S., Smith, P., and Smith, J. U., 38, NATO ASI series I, 111-132, Springer, Berlin Heidelberg New York, 1996.

Monod, J.: The growth of bacterial cultures, Annual Review of Microbiology, 3, 371-394, 1949.

Moorhead, D. L. and Sinsabaugh, R. L.: A theoretical model of litter decay and microbial interaction, Ecol. Monogr., 76, 151-174, 2006.

Neill, C. and Gignoux, J.: Soil organic matter decomposition driven by microbial growth: A simple model for a complex network of interactions, Soil Biol. Biochem., 38, 803-811, 2006.

Norby, R. J., DeLucia, E. H., Gielen, B., Calfapietra, C., Giardina, C. P., King, J. S., Ledford, J., McCarthy, H. R., Moore, D. J. P., Ceulemans, R., Angelis, P. D., Finzi, A. C., Karnosky, D. F., Kubiske, M. E., Lukac, M., Pregitzer, K. S., ScarasciaMugnozza, G. E., Schlesinger, W. H., and Oren, R.: Forest response to elevated $\mathrm{CO}_{2}$ is conserved across a broad range of productivity, P. Natl. A. Sci. USA, 102, 18052-18056, doi:10.1073/pnas.0509478102, 2005.

Norby, R. J., Warren, J. M., Iversen, C. M., Medlyn, B. E., and McMurtrie, R. E.: $\mathrm{CO}_{2}$ enhancement of forest productivity constrained by limited nitrogen availability, P. Natl. A. Sci., 107, 19368-19373, doi:10.1073/pnas.1006463107, 2010.

Panikov, N. S.: Microbial growth kinetics, Chapman Hall, London, 1995.

Panikov, N. S. and Sizova, M. V.: A kinetic method for estimating the biomass of microbial functional groups in soil, J. Microbiol. Meth., 24, 219-230, 1996.

Parnas, H.: Model for decomposition of organic material by microorganisms, Soil Biol. Biochem., 7, 161-169, doi:10.1016/0038-0717(75)90014-0, 1975.

Parton, W. J., Stewart, J. W. B., and Cole, C. V.: Dynamics of C, N, $\mathrm{P}$ and $\mathrm{S}$ in grassland soils - a model, Biogeochemistry, 5, 109131, 1988

Phillips, R. P., Finzi, A. C., and Bernhardt, E. S.: Enhanced root exudation induces microbial feedbacks to $\mathrm{N}$ cycling in a pine forest under long-term $\mathrm{CO}_{2}$ fumigation, Ecol. Lett., 14, 187-194, doi:10.1111/j.1461-0248.2010.01570.x, 2011.

Pirt, S.: The maintenance energy of bacteria in growing cultures, Proc. Roy. Soc. Lond. B, Biol. Sci., 163, 224-231, 1965.

Poll, C., Pagel, H., Devers-Lamrani, M., Martin-Laurent, F., Ingwersen, J., Streck, T., and Kandeler, E.: Regulation of bacterial and fungal MCPA degradation at the soil-litter interface, Soil Biol. Biochem., 42, 1879-1887, doi:10.1016/j.soilbio.2010.07.013, 2010.

Potter, C. S., Randerson, J. T., Field, C. B., Matson, P. A., Vitousek, P. M., Mooney, H. A., and Klooster, S. A.: Terrestrial ecosystem production: a process model based on global satellite and surface data, Global Biogeochem. Cy., 7, 811-841, 1993.

Raynaud, X., Lata, J. C., and Leadley, P. W.: Soil microbial loop and nutrient uptake by plants: a test using a coupled $\mathrm{C}: \mathrm{N}$ model of plant-microbial interactions, Plant Soil, 287, 95-116, doi:10.1007/s11104-006-9003-9, 2006.

Schimel, J. P. and Weintraub, M. N.: The implications of exoenzyme activity on microbial carbon and nitrogen limitation in soil: a theoretical model, Soil Biol. Biochem., 35, 549-563, 2003.

Schmidt, M. W. I., Torn, M. S., Abiven, S., Dittmar, T., Guggenberger, G., Janssens, I. A., Kleber, M., Kogel-Knabner, I., Lehmann, J., Manning, D. A. C., Nannipieri, P., Rasse, D. P., Weiner, S., and Trumbore, S. E.: Persistence of soil organic matter as an ecosystem property, Nature, 478, 49-56, doi:10.1038/nature10386, 2011.

Schmidt, S. K., Costello, E. K., Nemergut, D. R., Cleveland, C. C., Reed, S. C., Weintraub, M. N., Meyer, A. F., and Martin, A. M.: Biogeochemical consequences of rapid microbial turnover and seasonal succession in soil, Ecology, 88, 13791385, doi:10.1890/06-0164, 2007.

Segel, L. A. and Slemrod, M.: The quasi-steady-state assumption: a case study in perturbation, SIAM review, 446-477, 1989.

Smith, O. L.: Analytical model of the decomposition of soil organicMatter, Soil Biol. Biochem., 11, 585-606, doi:10.1016/00380717(79)90027-0, 1979.

Smith, P., Smith, J., and Powlson, D.: Soil organic matter network (SOMNET):1996 model and experimental metadata, 1996.

Thiessen, S., Gleixner, G., Wutzler, T., and Reichstein, M.: Both priming and temperature sensitivity of soil organic matter decomposition depend on microbial biomass - An incubation study, Soil Biol. Biochem., doi:10.1016/j.soilbio.2012.10.029, 2012.

Todd-Brown, K. E. O., Hopkins, F. M., Kivlin, S. N., Talbot, J. M., and Allison, S. D.: A framework for representing microbial decomposition in coupled climate models, Biogeochemistry, 109, 19-33, doi:10.1007/s10533-011-9635-6, 2012.

Treseder, K., Balser, T., Bradford, M., Brodie, E., Dubinsky, E., Eviner, V., Hofmockel, K., Lennon, J., Levine, U., MacGregor, B., Pett-Ridge, J., and Waldrop, M.: Integrating microbial ecology into ecosystem models: challenges and priorities, Biogeochemistry, 1-12, doi:10.1007/s10533-011-9636-5, 2011.

Trueman, R. J. and Gonzalez-Meler, M. A.: Accelerated belowground $\mathrm{C}$ cycling in a managed agriforest ecosystem exposed to elevated carbon dioxide concentrations, Glob. Change Biol., 11, 1258-1271, 2005.

van Bodegom, P.: Microbial maintenance: A critical review on its quantification, Microb. Ecol., 53, 513-523, 2007. 
Wutzler, T. and Reichstein, M.: Colimitation of decomposition by substrate and decomposers - a comparison of model formulations, Biogeosciences, 5, 749-759, doi:10.5194/bg-5-749-2008, 2008 .
Wutzler, T., Blagodatsky, S., Blagodatskaya, E., and Kuzyakov, Y.: Soil microbial biomass and its activity estimated by kinetic respiration analysis - Statistical guidelines, Soil Biol. Biochem., 45, 102-112, doi:10.1016/j.soilbio.2011.10.004, 2012. 